simplified or even distorted. This progressive picture also results in the omission of thought which does not fit into the pattern, the most notable example being twentieth century developmental biology.

Jacob's rigorously internalist approach also seems to be in conflict with his historiographic principles and results in some disappointingly conventional interpretations. Evolutionary thought, for example, is described in the programme as a product of "mid-nineteenth century thought as a whole", yet it is actually discussed in a very conventional fashion as an internal problem in biology, centring on the issue of the contingency of the living world, with a reference to similar ideas in contemporary statistical mechanics. This, in my view, is neither an adequate nor a particularly illuminating account of a transformation in thought involving ideas on God, man, nature and society and their interrelations.

On the other hand, problems also arise when Jacob applies his historiographic principles. The notion of relatively discontinuous domains of thought results in an historical picture in which the real continuities which exist are often obscured, and one which is often too schematic. His chapter on the "Visible Structure", which is concerned with seventeenth century thought, suffers as a consequence of this, even though parts of it are fascinating. His belief that "mechanism, despite its limitations, represented the only attitude compatible with knowledge of that time" and that other metaphysical principles were not scientifically productive but were merely of "ethical" or "philosophical" significance, seems to me to do violence to the richness and complexity of seventeenth century thought and results in misleading discussions of, for example, the discovery of microorganisms and the circulation of the blood. In these examples it seems that, although Jacob recognises that "objects" can form the subject of discourse in more than one domain, he believes that they are only accessible to investigation which is scientific and productive within a unique domain which is in "harmony" with their "nature". This presupposes that the "nature" of an "object" is completely independent of the theoretical framework in which that object is considered; a debatable assumption.

The final chapter, "The Integron", is clearly written by Jacob the biologist, and contains a discussion of some current views of the organisation of living systems. It is surprisingly uncritical and tends to confirm my suspicion that Jacob the biologist was the dominant personality in the writing of the whole book, for reverse or Whig history is, by and large, intended to justify the present state of affairs and to encourage us to accept it uncritically. On the other hand, the sort of history in which Jacob the historian is interested, the sort which asks the question "How is it possible for anyone to believe that?", has the goal of making us ask the same question with respect to our own beliefs, and therefore, of freeing us from the spectacles of habit and from the tyranny of our own artefacts. Jacob seems to be aware of this but evades coming to grips with it. In the final paragraph of the book he writes: "There are perhaps other possible coherences in descriptions. But science is enclosed in its own explanatory system and cannot escape from it". This is to raise the possibility of freedom, and therefore the necessity of choice, and then immediately to reject it by picturing science as an autonomous and alien thing; the "Russian doll" as a Petrushka, an artefact with a life of its own. It is to evade the fact that we are responsible for all our artefacts, including our "beliefs" and our "knowledge".

\section{Gerald Webster}

\section{Stimulating immunity}

Chemical and Biological Basis of Adjuvants. By P. Jollés and A. Paraf. Pp. viii +153. (Molecular Biology, Biochemistry and Biophysics, 13.) (Springer-Verlag: Berlin and New York, 1973.) $£ 7.90$.

AT best the subject of immunological adjuvants consisted of a potpourri of related phenomena: the publication of this monograph has to some extent improved the situation.

The authors have striven hard to obtain order and consistency which they achieved with respect to the chemical basis of adjuvants, although it has been done by introducing a noticeable degree of repetition. I found the earlier chapters especially informative with regard to the adjuvant materials of mycobacterial origin. In the area of cellular immunology, Jollés and Paraf have not achieved such clarity and there is no coherent discussion of immunopotentiation by substances acting on populations of differentiating cells.

I found the last chapter on the practical uses of adjuvants very incomplete and nothing like as scholarly as the earlier chapters. It would have been useful to have had a more critical and detailed discussion of recent French work where certain bacterial vaccines ( $C$. parvum; $\mathrm{BCG})$ have been used in the treatment of leukaemias. Direct toxicity is an important consideration and is adequately discussed; however only brief mention is made of the danger of adjuvants stimulating unwanted responses to autoantigens.

The book is well produced, and I noted few typographical errors. Its usefulness might have been increased if the bibliography had been made to serve additionally as an author index, simply by adding the page numbers of each citation after each listed reference. 'Adjuvant workers' should find this monograph worth buying.

\section{W. DRESSER}

\section{Natives of Canada}

Athapaskan Adaptations. By James W. Vanstone. Pp. $x+145$. (Worlds of Man: Cultural Ecology Series.) (Aldine: Chicago, April 1974.) $\$ 7.50$ cloth; $\$ 2.50$ paper.

THE Athapaskan speaking peoples occupy a vast forest region of northwest Canada and most of the land surface of Alaska. As Walter Goldschmidt the series editor suggests in the foreword, Athapaskan culture was less dramatic than the Northwest Coast or the Plains types, but no less adaptive; "a cultural flexibility, a quiet competence, a sustained ability to blend in with local environment" (page vii). The Athapaskan groups are seen as small communities of hunters and fishermen adapted to salmon fishing in the Pacific drainage lowlands, collective caribou hunts in the open northern regions, and more solitary moose hunting in the dense forested southern regions of Great Slave Lake.

The book is an attempt to present a very generalised account of the ecology and social organisation of the Athapaskan groups at the time of contact with European and Russian entrepreneurs about $1750 \mathrm{AD}$. It is based on the current research of many scholars in the field, as well as those of the 1950s and the 1920s. In addition there are two principal sources from the early period, namely Samuel Hearne's account of his trip to the Coppermine River, NWT Canada of 1769-72 and Henry Allen's to the Ahtna of the Copper River, Alaska in 1885 .

The linguistic units were divided into small, mobile task forces of hunters and fishermen, often widely separated if not isolated. Economic variations from this pattern were minor. But the author demonstrates an unaccountable variation of social practice. Among the 'Northern Athapaskan' some units have hereditary leadership, others have none. There is bilateral descent in some while others have matrilineal sibs; some have group and some have individual ceremonies. There is both matrilocal and fiexible residence patterns, and a modified male vision quest is present in some. 